\title{
Recycling of Glutathione during Oxidative Stress in Erythrocytes of the Newborn
}

\author{
PIETER C. ClAHSEN, RALF M. W. MOISON, CARLO A. J. HOLTZER, AND \\ HOWARD M. BERGER \\ Department of Pediatrics, Neonatal Unit, University Hospital of Leiden, The Netherlands
}

\begin{abstract}
The ability of erythrocytes from newborn babies and adults to maintain reduced glutathione levels during oxidative stress was studied. In vitro incubation of erythrocytes with $\mathrm{H}_{2} \mathrm{O}_{2}$, with or without inactivation of catalase, caused a rapid depletion of reduced glutathione (GSH) and concomitant accumulation of oxidized glutathione followed by recovery of GSH and fall of oxidized glutathione to initial values in all subjects. Inactivation of catalase resulted in a $50 \%$ loss of intracellular glutathione $(p<0.005)$, a larger maximum GSH depletion $(p<0.05)$, and a longer GSH recovery time $(p<0.005)$. Erythrocytes from newborn babies showed a smaller maximum GSH depletion $(p<0.05)$ and a shorter GSH recovery time $(p$ $<0.005)$ compared with those from adults. These differences between the newborn and adult groups persisted after inactivation of catalase. An increase in maximum GSH depletion and GSH recovery time $(p<0.005)$ was observed when a lower hematocrit was used for these GSH recovery studies. Effective glutathione recycling in erythrocytes may protect immature tissues of the newborn baby from peroxidative damage. (Pediatr Res 32: 399-402, 1992)
\end{abstract}

\section{Abbreviations}

GSH, reduced glutathione

GSSG, oxidized glutathione

In vitro and in vivo studies have shown that the erythrocytes of adult animals can protect other tissues, e.g. lung, against damage induced by reactive oxygen species (1). Erythrocytes can catabolize an $\mathrm{H}_{2} \mathrm{O}_{2}$ load produced by leukocytes (2) and have been shown to protect both cultured pulmonary endothelial cells (3) and the whole lung $(4,5)$ from oxidative damage. The action of catalase and the glutathione recycling system is believed to be the key factor in this protective mechanism (1).

The preterm baby has poorly developed antioxidant enzyme systems in various organs, e.g. lung, and is susceptible to oxygeninduced tissue damage, e.g. bronchopulmonary dysplasia $(6,7)$. Thus, the ability of the erythrocyte to catabolize $\mathrm{H}_{2} \mathrm{O}_{2}$ may be of particular importance in these patients. The ability of the erythrocyte to handle oxidative stress induced by $\mathrm{H}_{2} \mathrm{O}_{2}$ can be assessed in vitro by serially measuring the initial fall of GSH and the concomitant rise of GSSG and the subsequent recovery of GSH and fall of GSSG to initial values. Glutathione recycling has already been used to assess the antioxidant capacity of erythrocytes of adults $(8)$ and cell cultures $(9,10)$. We compared

Received January 14, 1992; accepted May 12, 1992

Correspondence and reprint requests: Howard M. Berger, Department of Pediatrics, Neonatal Unit, University Hospital of Leiden, P. O. Box 9600, 2300 RC Leiden, The Netherlands.

Supported in part by funds from the Gisela Thier Foundation and Milupa International. glutathione recycling during exposure to $\mathrm{H}_{2} \mathrm{O}_{2}$ in erythrocytes of newborn babies and adults. The erythrocyte activities of enzymes responsible for $\mathrm{H}_{2} \mathrm{O}_{2}$ catabolism, i.e. catalase, glutathione peroxidase, and glutathione reductase, were also measured.

\section{MATERIALS AND METHODS}

This study was approved by the Scientific Committee of the Department of Pediatrics and the Ethical Committee of the University Hospital of Leiden.

Patients. Umbilical cord blood samples were obtained from eight preterm and nine term infants (gestational age [mean (SD)] 32.9 (2.4) and 40.2 (1.5) wk, respectively\} within 15 min after delivery of the placenta. The babies were of normal birth weight (10th-90th percentile) and showed no signs of birth asphyxia (Apgar score $1 \mathrm{~min} \geq 9$, umbilical vein $\mathrm{pH} \geq 7.25$ ), respiratory distress, or infection. Their mothers, healthy Caucasian nonsmokers (3), did not receive vitamin or iron supplements. Venous blood samples were taken from 10 healthy Caucasian volunteers lage [mean (SD)] $24.9(2.4)$ y), who were nonsmokers.

From an additional group of 10 healthy term infants (gestational age [mean (SD) 40.6 (1.4) wk, other characteristics as above) umbilical cord blood samples were obtained to study in vitro the influence of the hematocrit on glutathione recycling.

Procedure. Blood was gently withdrawn $(1.1-\mathrm{mm}$ diameter needle) into heparinized tubes and immediately centrifuged $(750$ $\times g, 10 \mathrm{~min})$. Plasma and buffy coat were discarded and erythrocytes were washed twice in PBS $(500 \times \mathrm{g}, 10 \mathrm{~min})$. Aliquots of packed cells diluted in PBS (40X) with or without $1 \mathrm{mM}$ added sodium azide (a catalase inhibitor) were incubated with $\mathrm{H}_{2} \mathrm{O}_{2}(400 \mu \mathrm{M})$ and glucose $(5 \mathrm{mM})$ in a shaking water bath $\left(37^{\circ} \mathrm{C}\right)$ for $30 \mathrm{~min}$. Control incubations were performed in the absence of $\mathrm{H}_{2} \mathrm{O}_{2}$. Samples were withdrawn at specified time intervals and, after preparation, stored at $-20^{\circ} \mathrm{C}$ until spectrophotometric flow injection analysis of total glutathione (GSH + GSSG) and GSSG (11). Initial GSH (total glutathione minus GSSG) and GSSG concentrations were calculated using a GSSG standard (11) and expressed as $\mu \mathrm{mol} / \mathrm{g} \mathrm{Hb}$. To analyze changes with time during incubation with $\mathrm{H}_{2} \mathrm{O}_{2}$, the $\mathrm{GSH}$ level was expressed as the percentage of total glutathione. The following parameters were then calculated (Fig. 1): maximum GSH depletion, i.e. initial GSH\% minus lowest GSH\%; GSH depletion time, i.e. time at which maximum GSH depletion occurred; and GSH recovery time, i.e. time at which GSH recovered to $80 \%$ of its initial value. In preliminary studies, the occurrence of membrane lipid peroxidation during glutathione recycling was assessed by measuring thiobarbituric acid reactive substances in newborn and adult erythrocytes. In the absence of azide, no lipid peroxidation was observed and in the presence of azide a small increase in thiobarbituric acid reactive substances occurred, but this did not differ between the two patient groups.

The influence of the hematocrit on glutathione recycling was studied in vitro. A dilution of $40 \times$ (see above) served as a control and a dilution of $30 \times$ (high hematocrit) and $80 \times$ (low hematocrit) 


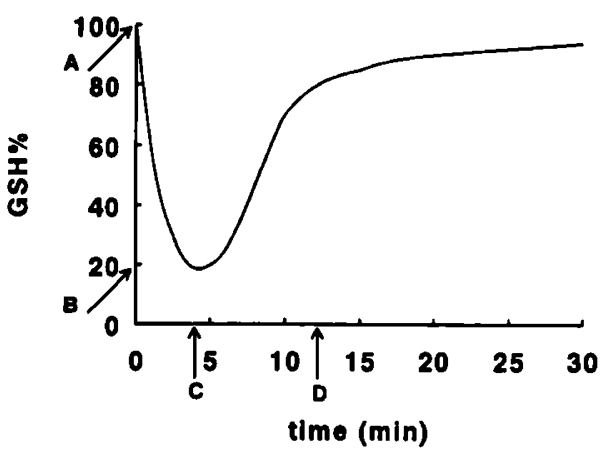

Fig. 1. The changes in GSH\% induced by incubation of erythrocytes with $\mathrm{H}_{2} \mathrm{O}_{2}$. GSH parameters were measured as follows: $l$ ) maximum GSH depletion, i.e. initial GSH\% (point $A$ ) minus lowest GSH\% (point B); 2) GSH depletion time, i.e. time at which maximum GSH depletion occurred (point C); and 3) GSH recovery time, i.e. time at which GSH recovered to $80 \%$ of its initial value (point $D$ ).

as a model for polycythemia and anemia, respectively. Incubations without sodium azide were performed as described above.

Enzymes. Activities of catalase (EC 1.11.1.6), glutathione peroxidase (EC 1.11.1.9), and glutathione reductase (EC 1.6.4.2) were measured in erythrocyte hemolysates using standard spectrophotometric techniques (12-14).

Reagents. All reagents were of the best grade commercially available. $\mathrm{H}_{2} \mathrm{O}_{2}$ and sodium azide pro analysi were obtained from Merck (Darmstadt, Germany) and GSSG (grade IV) was obtained from Sigma (St. Louis, MO).

Statistics. All results are reported as mean and SD or median and range. The SPSS-PC ${ }^{+}$software (version 3.0) was used for statistical analysis. Differences in maximum GSH depletion between the preterm, term, and adult groups were tested by pairwise comparisons using the Mann-Whitney test; the influence of azide on this parameter within each of the groups was tested using the Wilcoxon test. Differences in maximum GSH depletion produced by altering the hematocrit were tested by pair-wise comparisons using the Wilcoxon test. For all other variables, the unpaired and paired $t$ test were used. The correlation between gestational age and GSH recovery time was tested by Pearson's method. Values of $p<0.05$ were regarded as significant.

\section{RESULTS}

Initial erythrocyte GSH concentrations were higher in the preterm and term babies than in adults [12.0 (2.6), $13.0(4.6)$, and $9.6(2.0) \mu \mathrm{mol} / \mathrm{g} \mathrm{Hb}$, respectively, $p<0.05]$. The initial GSH\% of the total glutathione concentration was similar in all groups [99.2 (1.1)\%]. In the newborn babies, catalase and glutathione peroxidase activities were lower $(p<0.05)$ and glutathione reductase activity was higher $(p<0.05)$ than in the adults (results not shown).

The total glutathione level was stable during control incubations and incubations with $\mathrm{H}_{2} \mathrm{O}_{2}$ without azide in all groups. However, in the presence of $\mathrm{H}_{2} \mathrm{O}_{2}$ and azide, total glutathione gradually decreased to $50 \%$ of the initial value after incubation for $30 \mathrm{~min}(p<0.005)$. This decline did not differ between the three groups.

GSH\% and GSSG\% were stable during control incubations. However, in the presence of $\mathrm{H}_{2} \mathrm{O}_{2}$ with or without azide, GSH\% and GSSG\% changed significantly; immediately after $\mathrm{H}_{2} \mathrm{O}_{2}$ addition, GSH\% fell with a concomitant increase in GSSG\%, followed by a gradual recovery of GSH\% to its initial high level and return of GSSG\% to its initial low level. Figure 2 shows the serial changes in GSH\% with and without azide in the three groups. Within all groups, inactivation of catalase produced a larger maximum GSH depletion $(p<0.05)$ and a longer GSH depletion time $(p<0.05)$ and GSH recovery time $(p<0.005)$. In the absence of azide, erythrocytes of newborn babies showed
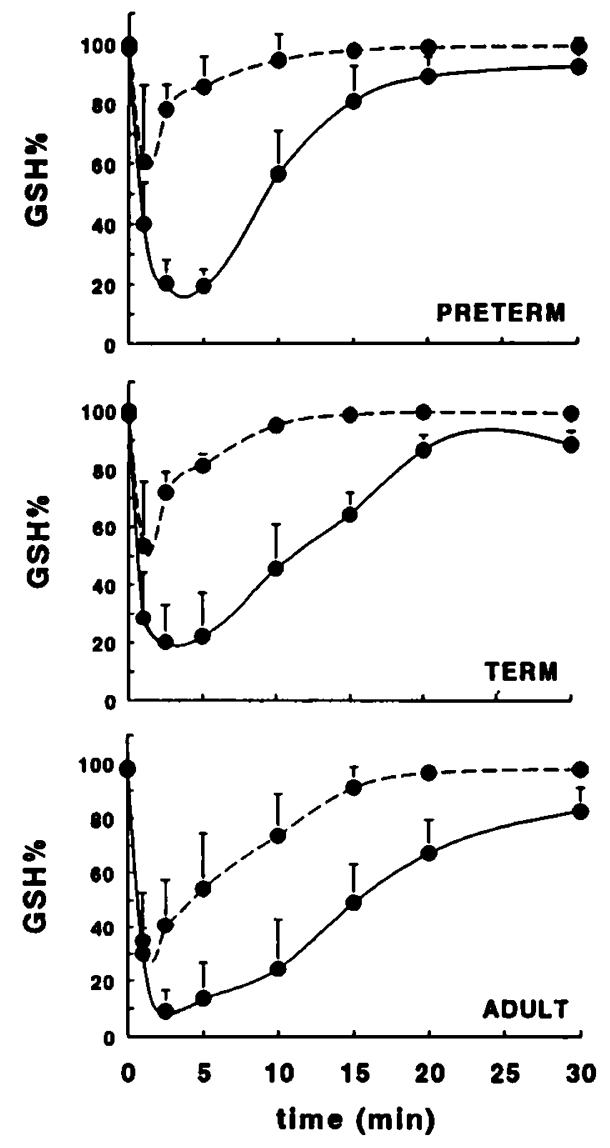

Fig. 2. Changes in GSH\% (mean, SD) in the preterm, term, and adult groups in erythrocytes incubated with $\mathrm{H}_{2} \mathrm{O}_{2}$ in the absence (-..-) and the presence $(-)$ of azide.

Table 1. Influence of hematocrit on GSH parameters in cord blood erythrocytes incubated with $\mathrm{H}_{2} \mathrm{O}_{2}$ without addition of azide

\begin{tabular}{llll}
\hline & High hematocrit & \multicolumn{1}{c}{ Control } & Low hematocrit \\
\hline $\begin{array}{l}\text { Maximum GSH } \\
\text { depletion } \\
(\%)^{*}\end{array}$ & $31.8[18.1-46.8]$ & $39.9[25.0-49.5]$ & $57.0 \dagger[45.2-64.1]$ \\
$\begin{array}{l}\text { GSH depletion } \\
\text { time (min) } \ddagger\end{array}$ & $1.3(0.2)$ & $1.3(0.1)$ & $1.4(0.1)$ \\
$\begin{array}{l}\text { GSH recovery } \\
\text { time (min) } \ddagger\end{array}$ & $2.3(1.0)$ & $2.6(0.6)$ & $5.1 \dagger(1.0)$ \\
\hline
\end{tabular}

* Median [range].

$\dagger p<0.005$ compared with control. $\ddagger$ Mean (SD).

a smaller maximum GSH depletion $(p<0.05)$ and a shorter GSH recovery time $(p<0.005)$ but no difference in GSH depletion time compared to those of adults. These differences persisted after inactivation of catalase. However, in the newborn group, the preterm babies had a shorter GSH recovery time than the term babies $(p<0.01)$ and GSH recovery time correlated with gestational age $(r=0.68, p<0.02, n=12)$.

Table 1 shows the influence of erythrocyte concentration on the GSH parameters. The smaller maximum GSH depletion and shorter GSH recovery time in the "high hematocrit" samples compared to the control samples were not statistically significant. However, there was a significantly greater maximum GSH depletion and longer GSH recovery time in the "low hematocrit" samples $(p<0.005)$. The hematocrit had no influence on GSH depletion time. 


\section{DISCUSSION}

Erythrocytes are exposed to high oxygen concentrations and possess powerful antioxidant defenses. An important oxidant in the blood is $\mathrm{H}_{2} \mathrm{O}_{2}$, which is produced physiologically, e.g. by erythrocytes (15), and pathologically, e.g. by activated polymorphonuclear leukocytes (16). Its catabolism by erythrocyte catalase and glutathione peroxidase is important in protecting not only the erythrocyte, but also other tissues, e.g. lung (1, 3-5). Catalase needs no additional cofactor for $\mathrm{H}_{2} \mathrm{O}_{2}$ catabolism. However, glutathione peroxidase requires $\mathrm{GSH}$ as a substrate and glutathione reductase-mediated reduction of GSSG recycles GSH, maintaining it at a high concentration. This glutathione recycling during oxidative stress has been studied in cell cultures $(9,10)$ and in erythrocytes of adults (8). However, in erythrocytes of the newborn, although the $\mathrm{H}_{2} \mathrm{O}_{2}$-induced fall of $\mathrm{GSH}$ has been studied $(17,18)$, the characteristics of the recovery of GSH have not been studied previously.

Our results provide further evidence that catalase plays an important role in handling an $\mathrm{H}_{2} \mathrm{O}_{2}$ load in the erythrocyte (1, 19, 20). Inactivation of catalase by the addition of azide had a marked influence on both total glutathione and GSH. The glutathione recycling system was exposed to greater oxidative stress and larger amounts of GSSG were formed. It has been suggested that the GSSG can be lost as a result of formation of mixed disulfides with $\mathrm{Hb}(9)$ and active transport out of the cell $(9,21)$. These mechanisms could explain the $50 \%$ loss of total glutathione in our studies. The remaining glutathione was still recycled, although a greater maximum GSH depletion and a longer GSH recovery time occurred in all groups. In the newborn group, the preterm babies now had a shorter GSH recovery time than the term babies.

Our results confirm the lower catalase and glutathione peroxidase levels and the higher glutathione reductase and GSH levels in erythrocytes of newborn babies compared with those of adults $(18,22-24)$. These findings could be due to the raised reticulocyte count typically present in cord blood. However, adults with a reticulocyte count similar to the newborn show an increased glutathione peroxidase activity and no increase in GSH level (22). Furthermore, in adults with a greatly increased reticulocyte count, the glutathione reductase activity is still much lower than that in newborn babies (25). The regulation of expression of the enzymes involved in glutathione recycling appears to be different in fetal erythrocytes than in those from adults $(22,25)$. This regulation appears to change gradually: in subjects aged 1 mo to $63 \mathrm{y}$, glutathione peroxidase activity correlated positively and glutathione reductase activity negatively with age (26).

It has been argued that the smaller fall in GSH levels during oxidative stress in erythrocytes of newborn babies compared to adults is due to the decreased glutathione peroxidase level resulting in an inability to utilize GSH (27). However, it is well recognized that an enzyme concentration measured in a hemolysate may not reflect its actual activity in the intact erythrocyte $(18,28)$. Glader and Conrad (18) showed that exposure of erythrocytes to $\mathrm{H}_{2} \mathrm{O}_{2}$ stress after inhibiting catalase and glutathione reductase activities resulted in the oxidation of similar amounts of GSH in erythrocytes of newborn babies and adults. This demonstrated that the lower erythrocyte glutathione peroxidase level of newborn babies was not functionally significant (18). Our findings support this conclusion: if the glutathione peroxidase activity was limited, maximum GSH depletion would have occurred later than in erythrocytes of adults, and a greater $\mathrm{H}_{2} \mathrm{O}_{2}$ load, due to inactivation of catalase, would not have produced a greater maximum GSH depletion. It is interesting that the raised glutathione reductase level in erythrocytes of newborn babies has not been used to explain the GSH levels during oxidative stress. We suggest that the decreased fall in GSH levels recorded in other studies $(18,27)$ may not have been due to lack of oxidation to GSSG because of decreased glutathione peroxidase activity, but rather due to rapid reduction of GSSG back to GSH because of increased glutathione reductase activity. This interpretation is not supported by a study using a nonphysiologic oxidant: a raised glutathione reductase activity in erythrocytes of newborn babies did not result in a shorter GSH recovery time (28). These different results may be explained by differences in the oxidant used and the patient populations studied [no details of the babies' gestational age, nutritional state, and condition at birth were given (28)].

An alternative explanation for the more efficient glutathione recycling in erythrocytes of newborn babies could be that their erythrocyte membranes were more susceptible to $\mathrm{H}_{2} \mathrm{O}_{2}$ damage $(17,29,30)$. Preferential targeting of these membranes might reduce the $\mathrm{H}_{2} \mathrm{O}_{2}$ load on their glutathione recycling system, resulting in a smaller GSH depletion and a shorter GSH recovery time. However, this explanation is not likely because we used a much lower $\mathrm{H}_{2} \mathrm{O}_{2}$ concentration than is used to study the susceptibility of erythrocyte membranes to lipid peroxidation, i.e $400 \mu \mathrm{M}$ versus $10 \mathrm{mM}$ (31) or $110 \mathrm{mM}$ (32). As discussed in Materials and Methods, this low $\mathrm{H}_{2} \mathrm{O}_{2}$ concentration produced no differences in lipid peroxidation between babies and adults. These findings support the contention that the glutathione recycling system of neonatal erythrocytes was subjected to an $\mathrm{H}_{2} \mathrm{O}_{2}$ load equal to that of the adult erythrocytes but was able to more efficiently catabolize the $\mathrm{H}_{2} \mathrm{O}_{2}$.

Clinical implications. At birth, newborn babies have a relative polycythemia and their erythrocytes have a higher GSH concentration and a more efficient glutathione recycling system than adults. This effective system for $\mathrm{H}_{2} \mathrm{O}_{2}$ catabolism may help protect against oxygen toxicity by compensating for the deficient antioxidant capacity in other tissues, e.g. lung $(1,7)$. The efficiency of this system could be influenced postnatally by quantitative and qualitative changes in the erythrocytes. It has been suggested that transfusions or exchange transfusions may predispose babies to oxygen toxicity because of a greater oxygen dissociation from adult erythrocytes (33). However, the results from this study and our previous study on plasma antioxidants (34) suggest that the influence of transfusions on oxygen toxicity is complex and not always disadvantageous. Transfusion of an anemic baby could improve its total antioxidant capacity by increasing the contribution of the erythrocytes and plasma. Selenium and riboflavin are cofactors of glutathione peroxidase and glutathione reductase, respectively, and their bioavailability could be influenced by the nutrition and therapy of the baby. For example, human milk contains more selenium than preterm formula (35) and phototherapy can decrease plasma riboflavin levels (36).

Acknowledgments. The authors thank the obstetric nursing staff for their help with collecting blood specimens and Ernst Houdkamp for his technical assistance with the flow injection analysis system.

\section{REFERENCES}

1. Heffner JE, Repine JE 1989 Pulmonary strategies of antioxidant defense. Am Rev Respir Dis 140:531-554

2. Test ST, Weiss SJ 1984 Quantitative and temporal characterization of the extracellular $\mathrm{H}_{2} \mathrm{O}_{2}$ pool generated by human neutrophils. J Biol Chem 259:399-405

3. Toth KM, Berger EM, Beehler CJ, Repine JE 1986 Erythrocytes from cigarette smokers contain more glutathione and catalase and protect endothelial cells from hydrogen peroxide better than do erythrocytes from nonsmokers. Am Rev Respir Dis 134:281-284

4. Toth KM, Clifford DP, Berger EM, White CW, Repine JE 1984 Intact human erythrocytes prevent hydrogen peroxide-mediated damage to isolated perfused rat lungs and cultured bovine pulmonary artery endothelial cells. J Clin Invest 74:292-295

5. Van Asbeck BS, Hoidal J, Vercelotti GM, Schwartz BA, Moldow CF, Jacobs HS 1985 Protection against lethal hyperoxia by tracheal insufflation of erythrocytes: role of red cell glutathione. Science 227:756-.759

6. Phelps DL 1982 Neonatal oxygen toxicity: is it preventable? Pediatr Clin North Am 29:1233-124!

7. Wispe JR, Roberts RJ 1988 Development of antioxidant systems. In: Merritt TA, Northway Jr WH, Boynton BR (eds) Bronchopulmonary Dysplasia. 
Blackwell Scientific Publications. Boston, pp 103-116

8. Koster JF, Slee RG, Rutten-van Beysterveld CCM, Montfoort A 1983 The effect of $(13 \mathrm{OOH})$ linoleic acid on human erythrocytes and on erythrocyte ghosts. Biochim Biophys Acta 754:238-242

9. Spector A. Huang RC, Wang G 1985 The effect of $\mathrm{H}_{2} \mathrm{O}_{2}$ on lens epithelial cell glutathione. Curr Eye Res 4:1289-1295

10. Jongkind JF, Verkerk A, Baggen RGA 1989 Glutathione metabolism of human vascular endothelial cells under peroxidative stress. Free Radic Biol Med 7:507-512

11. Redegeld FAM, van Opstal MAJ, Houdkamp E, van Bennekom WP 1988 Determination of glutathione in biological material by flow injection analysis using an enzymatic recycling reaction. Anal Biochem 174:489-495

12. Aebi H 1984 Catalase in vitro. In: Packer L (ed) Oxygen Radicals in Biological Systems, Vol 105, Methods in Enzymology. Academic Press, Orlando, FL, pp $121-126$

13. Flohé L, Günzler WA 1984 Assays of glutathione peroxidase. In: Packer L (ed) Oxygen Radicals in Biological Systems, Vol 105, Methods in Enzymology. Academic Press, Orlando, FL, pp 114-120

14. Carlberg 1, Mannervik B 1985 Glutathione reductase. In: Meister A (ed) Glutamate, Glutamine, Glutathione and Related Compounds, Vol 113, Methods in Enzymology. Academic Press, Orlando, FL, pp 484-490

15. Bracci R, Benedetti PA, Ciambellotti V 1970 Hydrogen peroxide generation in the erythrocytes of newborn infants. Biol Neonate 15:135-141

16. Root RK, Metcalf JA $1977 \mathrm{H}_{2} \mathrm{O}_{2}$ release from human granulocytes during phagocytosis. J Clin Invest 60:1266-1279

17. Gross RT, Bracci R, Rudolph N, Schroeder E, Kochen JA 1967 Hydrogen peroxide toxicity and detoxification in the erythrocytes of newborn infants. Blood 29:481-493

18. Glader BE, Conrad ME 1972 Decreased glutathione peroxidase in neonatal erythrocytes: lack of relation to hydrogen peroxide metabolism. Pediatr Res 6:900-904

19. Agar NS, Sadrzadeh SMH, Hallaway PE, Eaton JW 1986 Erythrocyte catalase. A somatic oxidant defense? J Clin Invest 77:319-321

20. Gaetani GF, Galiano S, Canepa L, Ferraris AM, Kirkman HN 1989 Catalase and glutathione peroxidase are equally active in detoxification of hydrogen peroxide in human erythrocytes. Blood 73:334-339

21. Beutler $E 1983$ Active transport of glutathione disulfide from erythrocytes. In: Larsson A (ed) Functions of Glutathione: Biochemical, Physiological. Toxicological and Clinical Aspects. Raven Press, New York, pp 65-74
22. Konrad PN, Valentine WN, Paglia DE 1972 Enzymatic activities and glutathione content of erythrocytes in the newborn: comparison with red cells of older normal subjects and those with comparable reticulocytosis. Acta Haematol (Basel) 48:193-201

23. Ripalda MJ, Rudolph N, Wong SL 1989 Developmental patterns of antioxidant defense mechanisms in human erythrocytes. Pediatr Res 26:366-369

24. Lestas AN, Rodeck $\mathrm{CH} 1984$ Normal glutathione content and some related enzyme activities in the fetal erythrocytes. Br J Haematol 57:695-702

25. Mohrenweiser HW, Fielek S, Wurzinger KH 1981 Characteristics of enzymes of erythrocytes from newborn infants and adults: activity, thermostability, and electrophoretic profile as a function of cell age. Am J Hematol 11:125136

26. Ceballos-Picot I, Trivier J, Nicole A, Sinet P, Thevenin M 1992 Age-correlated modifications of copper-zinc superoxide dismutase and glutathione-related enzyme activities in human erythrocytes. Clin Chem 38:66-70

27. Shahal Y, Bauminger ER, Zmora E, Katz M, Mazor D, Horn S, Meyerstein N 1991 Oxidative stress in newborn erythrocytes. Pediatr Res 29:119-122

28. Yawata Y, Tanaka KR 1973 Studies on glutathione reductase and regeneration of reduced glutathione in normal adult and cord red cells. Clin Chim Acta 46:267-275

29. Jain SL 1989 The neonatal erythrocyte and its oxidative susceptibility. Semin Hematol 26:286-300

30. Lubin B, Oski FA 1972 Red cell metabolism in the newborn infant. VI. Irreversible oxidant-induced injury. J Pediatr 81:698-704

31. Stocks J, Dormandy TL 1971 The autoxidation of human red cell lipids induced by hydrogen peroxide. $\mathrm{Br} \mathrm{J}$ Haematol 20:95-111

32. Cynamon HA, Isenberg JN, Nguyen $\mathrm{CH} 1985$ Erythrocyte malondialdehyde release in vitro: a functional measure of vitamin E status. Clin Chim Acta 151:169-176

33. Lucey JF, Dangman B 1984 A reexamination of the role of oxygen in retrolental fibroplasia. Pediatrics 73:82-96

34. Lindeman JHN, Lentjes EGWM, Houdkamp E, van Zoeren-Grobben D, Schrijver J, Berger HM 1992 Effect of an exchange transfusion on plasma antioxidants in the newborn. Pediatrics 90:200-203

35. Smith AM, Chan GM, Moyer-Mileur LJ, Johnson CE, Gardner BR 1991 Selenium status of preterm infants fed human milk, preterm formula, or selenium-supplemented preterm formula. J Pediatr 119:429-433

36. Gromisch DS, Lopez R, Cole HS, Cooperman JN 1977 Light (phototherapy)induced riboflavin deficiency in the neonate. J Pediatr 90:118-122 